\title{
Electrochemical Oxidation of Methylene Blue in Aqueous Solution
}

\author{
H. M. A. Asghar, T. Ahmad, S. N. Hussain, and H. Sattar
}

\begin{abstract}
An electrochemical oxidation technique was used for mineralizing the methylene blue dye dissolved in water. For this purpose, an electrochemical cell was used consisting of electrodes made from stainless steel and graphite. The effect of various factors on dye removal was studied such as current density, treatment time and initial concentration of dye solution. A substantial increase in dye removal was found to be in direct proportion with initial dye concentration. However, the dye removal was found to be increased with an increase of treatment time up to 30-40 min and current density up to $0.06 \mathrm{~A}$ $\mathrm{cm}^{-2}$.
\end{abstract}

Index Terms-Electrochemical oxidation, methylene blue \& current density.

\section{INTRODUCTION}

Water is a fundamental requirement for all living bodies. It has a vital role for industrial operations. In near future, the availability of drinking water will be a challenge in all over the world. The term waste water treatment refers to the treatment of dissolved impurities collected and transported from industrial discharge effluents. Waste water can generally be classified into domestic and industrial. The waste water from each source may contain both dissolved and suspended impurities. The suspended particles can be removed by filtration where as dissolved contaminants required further treatment. The type of contaminant may vary with each type of discharge from industrial sector. These industries may include food processing units, dairy operations, meat packing, poultry, oil \& gas, paper, fertilizer, petrochemical etc. In addition to organic waste materials, inorganic pollutants may also present in water. The inorganic wastes may originate from metal plating, battery shops, furniture manufacturing, dry cleaning units etc. Waste water treatment can be classified into primary, secondary and tertiary treatments. It is desirable to remove suspended particles prior to treatment processes which may otherwise cause serious operational and mechanical problems. Pre-treatment is followed by primary treatment comprising of gravity settlers for the removal of total dissolved solids. Secondary and tertiary treatments are then followed. The environmental agencies have made strict rules and regulations for industries in order to treat their waste water to ppb and ppt levels. The colored organic compounds present in water may resist oxygen diffusion in to the aqueous phase. The presence of these contaminations stops the aerobic action in water as well. Even organic contaminations in small

Manuscript received September 30, 2014; revised December 29, 2014.

H. M. A. Asghar is with the University of the Punjab, Lahore, Pakistan (e-mail: engr_anwaar@yahoo.com). amount destroy the aquatic life. Some of the contaminants are still non-biodegradable which remain present in water for long time. The Royal Commission has set a standard of maximum value of BOD (Biological Oxygen Demand) in industrial effluents in order to remove all contaminations from water which shows the biodegradability of organic compounds while COD (Chemical Oxygen Demand) shows a precise measurement of presence of organic compounds in water [1]. A number of methods have been devised to remove contaminants from water such as adsorption, bacterial action, absorption, membrane, direct oxidation, reverse osmosis etc. In general these methods can be classified into three groups naming physical, chemical and biological. However, ultimate selection has always been challenging in the perspective of economical and process related constraints. Biological way of removing organic contaminants has always been popular due to cheaper in cost. However, with the development of biologically non-degradable organics complex derivatives, other treatment methods have emerged equally competitive.

A study on the fermentation of waste water of cassava was conducted. This method should be utilized on industrial scale for source of amylase. Treated waste water can be reused for different applications. Israel is using $70 \%$ of treated waste water for agriculture purpose. Treated waste water can also be used for drinking purposes as well, however many illness causing pathogens still exist in waste water. The 150 pathogens have been reported which may present in waste water however, with the passage of time more are being discovered [2]. There are biological, physical and chemical methods to treat waste water. Different systems can be designed like primary, secondary and tertiary treatment by combining any of these methods. Traditional water treatment processes are somehow restricted to destroy toxic and biologically non-degradable organic pollutants such as berbicides, pesticides and endocrine disrupting compounds which are found with relatively high concentrations in the aquatic environment. In addition to synthetically manufactured organic derivatives, these are released by various sources such as cow manure, sewage and solvents used in dry cleaning chemicals and detergents.

The study of electrochemical oxidation was started in $19^{\text {th }}$ century when the dissociation of cyanide into its ions was studied. In the last twenty years, the research has been focused to enhance the power of oxidants used for different industrial effluents on different operating conditions to improve the efficiency of the process. The anodic oxidation is an important method of electrochemical oxidation. High voltage is used with anode made of different materials like Pt. and BDD (boron doped diamond) etc. to generate hydroxyl radicals. The hydroxyl radical is an important oxidizing agent that reacts with organic compounds to produce carbon 
dioxide, water and inorganic ions. In this process, organic compounds in aqueous solutions are degraded by anodic process. Therefore, an electrochemical oxidation technique is widely being used for multiple industrial effluents. The efficiency of this process depends on various factors. For direct oxidation process, temperature does not have a significant impact on process output however, for meditate processes; temperature has its importance. The contributing factors are $\mathrm{pH}$ of the solution, time of oxidation, concentration of electrolyte, and concentration of required contaminants to be extracted. The material of which electrode is made is very important. The material should have following properties:

1) It should be highly electrically conductive.

2) It should have less cost to life ratio.

It should be physically and chemically stable with strong resistance to corrosion and erosion. The electrochemical oxidation has many benefits over other wastewater treatment technologies. Multiple industrial effluents can be treated using this method. The temperature and pressure conditions required for this method were reported to be comparatively low [3]. It is being practiced in a range of industrial effluents such as pulp and paper, petrochemical, pharmaceutical, textile and tanneries. It is also being used for Food industry as well like olive oil and dairy manure. [4]. Because of presence of sodium chloride in textile dyes the process of electrochemical oxidation is very easy to use without any addition of chemicals. The mechanism of electrochemical reactions involved is considered to be complex [5]. Although bye the use of biological treatment, the maximum amount of colored contaminations from waste water can be extracted but certainly there are also some drawbacks. These biological treatments are very friendly and cheap. Anaerobic decolourisation of azo dyes generates amines which have dangerous effects on living organisms in water [6]. Electrolyte solution is prepared by adding $\mathrm{NaSO}_{4}$ or $\mathrm{H}_{2} \mathrm{SO}_{4}$ $\mathrm{OR} \mathrm{NaCl}$. In order to avoid possibility of formation of toxic intermediates, $\mathrm{NaCl}$ is preferred. However, few drops of $\mathrm{HCl}$ may be added in order to control the solution $\mathrm{pH}$. It was suggested that electrode material should have high electrochemical activity [7]. The function of electrode is to produce large amount of free radicals as a result of electrolysis and permits mineralization of the organic compound.

The objective of this study was to investigate the effect of current density, electrochemical treatment time and initial dye concentration on electrochemical degradation (removal) of methyl blue from its aqueous solution through electrochemical potential.

\section{MATERIALS AND MethodS}

Stock solution of methylene blue (with purity 99\%) was prepared in distilled water. The brine solution $(1 \% \mathrm{w} / \mathrm{w})$ was prepared in distilled water and acidified at $\mathrm{pH} 2$ by adding few drops of $\mathrm{HCl}$. The acidified brine solution was used as catholyte. The aqueous solutions of methylene blue were analyzed using UV/Vis spectrophotometer (Perkin Elmer Lambda 25). The photometric analysis was conducted at a lambda max of $660 \mathrm{~nm}$. [6]
The electrochemical oxidation of methylene blue was conducted in an electrochemical cell as shown in Fig. 1. The cell comprised of two compartments naming anodic and cathodic as show in Fig. 1-Fig. 4 below. The anode was made of graphite and the cathode was made from a perforated sheet of stainless steel. Both the compartments were separated by placing a poly-ethylene based membrane (DARAMIC 350). The cathodic and anodic compartments were filled with catholyte and methylene blue solution respectively. The methylene blue solution was filled with a known concentration and after the treatment the remaining concentration was determined using spectrophotometer. After filling the said solutions in both the compartments, the electrodes were connected to a DC power supply. The effect of initial concentration, current density and treatment was studied with reference to the percent removal of methylene blue from its aqueous solution.

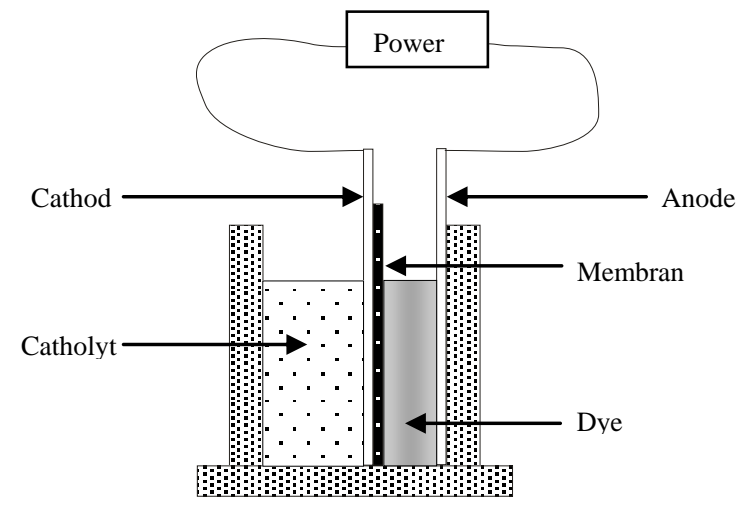

Fig. 1. Electrochemical cell used for electrochemical oxidation of methylene blue dissolved in water.

\section{RESULTS AND DisCUSSIONS}

In order to study the effect of electrochemical treatment time on dye removal, series of experiments were conducted for which a current density of $0.002 \mathrm{~A} / \mathrm{cm}^{2}$ and a concentration of $100 \mathrm{mg} / \mathrm{L}$ was maintained and kept constant for all experiments. The initial $\mathrm{pH}$ of dye solution was found to be at around 2. The result is shown in the Fig. 2 below. It is evident in Fig. 2 that dye removal is in direct proportion to the treatment time. The effect of treatment time was studied up to a maximum of $60 \mathrm{~min}$. Although, a treatment time of 40 min was found to be optimized for getting maximum dye removal through electrochemical oxidation. However, a treatment time of $30 \mathrm{~min}$ was selected as there was not a significant difference in dye against a treatment time of 40 $\min [8]$.

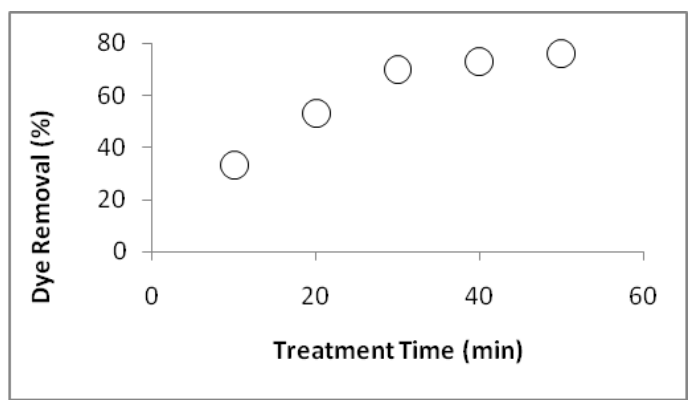

Fig. 2. Effect of treatment time on dye removal (\%). 
Based on these results, a treatment time of 30 min was selected for remaining experiments. It is notable that a sharp increase in dye removal was obtained in between the treatment time of 10-30 min and beyond this range there was a gradual increase in dye removal as a function of treatment time. It may be speculated due to some unwanted or side reactions which may proceed at longer treatment times. However, in order to validate this hypothesis, further research work is required [8]. These results were found consistent when compared with results as reported in past [9]-[14].

Fig. 3 shows the effect of initial dye concentration on its \%-removal through electrochemical oxidation. A current density of $0.002 \mathrm{~A} / \mathrm{cm}^{2}$ was maintained for a treatment time of $30 \mathrm{~min}$. The initial $\mathrm{pH}$ of dye solution was found to be 2 . An increase in dye removal was found with an increase of initial dye concentration. The effect of initial concentration was studied up to a range of $140 \mathrm{mg} / \mathrm{L}$ of dye solution. Lower dye concentrations might cause total dye removal and therefore, slightly higher range of dye solution was selected in order to carry out these experiments. A maximum of $78 \%$ dye removal was found against initial dye concentration of $140 \mathrm{mg} / \mathrm{L}$ and a minimum of $68 \%$ dye removal was observed at an initial concentration of $100 \mathrm{mg} / \mathrm{L}$ [8].

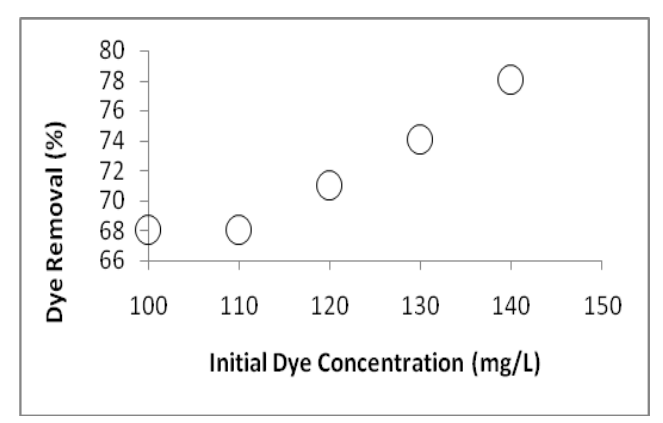

Fig. 3. Effect of initial dye concentration on dye removal through electrochemical oxidation [7].

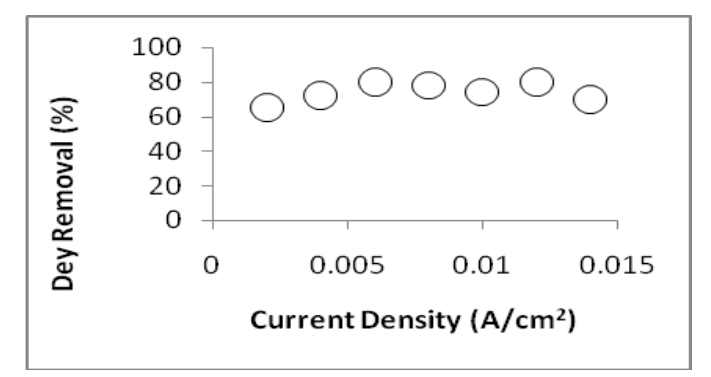

Fig. 4. Effect of current density on dye removal through electrochemical oxidation.

Experiments were conducted in order to investigate the effect of current density on dye removal through electrochemical oxidation. Fig. 4 presents the data points obtained through experiments. A slight increase in dye removal was noticed with an increase of current density up to a value of $0.008 \mathrm{~A} / \mathrm{cm}^{2}$ and beyond this range no significant change was noticed. High current density values may lead towards the formation of by-products by diminishing the actual dye removal however; it is speculation which may not be true. In order to validate the actual reason that why there was no further increase in dye removal beyond current density value of $0.008 \mathrm{~A} / \mathrm{cm}^{2}$. Further research work is recommended in order to investigate the hypothesis [8]. The effect of current density on the dye removal was found to be consistent with compared with the cased reported for the removal of acid violet 17 using modified graphite based adsorbent material [9]-[14].

Significant results on electrochemical regeneration have recently been reported which explained the exploitation of electrochemical oxidation of contaminating organic species adsorbed on the surface of graphite based adsorbents. The investigations revealed that breakdown products might formed during the electrochemical regeneration process of dissolved organic species. These breakdown products may include in liquid or gaseous form. The previous work was reported for the adsorption of various organic pollutants on the surface of solid graphite flake material followed by electrochemical regeneration. During electrochemical regeneration, electrochemical oxidation was supposed to be carried out in order to mineralize the adsorbed organic molecules on the surface of graphite intercalation based adsorbent material. However, further investigations are still in progress and authors assume this work to be of worth publishing once investigations have been accomplished. Similarly, during the electrochemical oxidation of methylene blue as investigated in an electrochemical cell as described in previous section might lead the formation of breakdown products. However, the formation of breakdown products which assumed to be formed have not been investigated as not being the scope of this work and will be reported in later stage (15-18). However, no formal study has yet been reported for the investigation of breakdown products generated during direct electrochemical oxidation of organic pollutants dissolved in water. It requires further investigations and therefore, will be addressed in separated project as not being under the scope of this research work.

\section{CONClusions}

The study comprised of methylene blue (dye) removal from its aqueous solution using electrochemical oxidation method. An electrochemical cell consisting of two compartments was used for this purpose. The results revealed that $\%$ removal of the methylene blue from aqueous solution was in direct proportion with its initial concentration. A treatment time of $40 \mathrm{~min}$ and current density of $0.06 \mathrm{~A} / \mathrm{cm}^{2}$ showed a maximum dye removal of up to $80 \%$ and no significant change in dye removal was observed beyond these limits.

\section{ACKNOWLEDGMENT}

The authors acknowledge the financial support granted by University of the Punjab, Lahore (PK).

\section{REFERENCES}

[1] H. M. A. Asghar, "Development of Graphitic Adsorbents for water treatment using adsorption and electrochemical regeneration," A thesis submitted to the University of Manchester for the degree of doctor of philosophy in the faculty of Engineering and physical Sciences, 2011.

[2] A. Ofoefule, E. Uzodinma, and C. Ibeto, "Waste water treatment options and its associated benefits," Biomass Unit, National Center of 
Energy Research \& Development University of Nigeria, Nsukka. Engu State Nigeria, pp. 3-5, 2009.

[3] A. Anglada, A. Urtiaga, and I. Ortiz, "Contributions of electrochemical oxidation to waste water treatment: Fundamentals and review of applications," pp. 1-7, 2009.

[4] S. Klamklang, H. Vergnes, K. Pruksathron, and A. Damronglerd. (2012). Electrochemical Incineration of Organic Pollutants for Wastewater Treatment Past, Present and Prospect. [Online]. pp. 5-10. Available: http://www.intechopen.com

[5] E. Kavitha, "Electrochemical oxidation of textile industry waste using DSA in tubular reactor," International Journal of Engineering Research and Applications, vol. 2, pp. 444-451, 2012.

[6] T. Marimuthu, S. Rajendran, and M. Manivannan, "A review on electrochemical decolourisation of dye effluent," vol. 2, pp. 4-7 2013.

[7] C. Comninellis, "Electrocatalysis in the electrochemica conversion/combustion of organic pollutants for waste water treatment," Electrochimical Acta, vol. 39, pp. 1857-1862, 1994.

[8] T. Ahmad, "MSc dissertation submitted to the University of the Punjab, Lahore," in partial fulfillment of MSc Engg. in Chemical Engineering, 2014.

[9] H. M. A. Asghar, S. N. Hussain, H. Sattar, N. W. Brown, and E. P. L. Roberts, "Improved phenol adsorption from aqueous solutions using electrically conducting adsorbents," The Korean Journal of Chemical Engineering, vol. 31, no. 5, pp. 834-840, 2014.

[10] H. M. A. Asghar, S. N. Hussain, H. Sattar, N. W. Brown, and E. P. L. Roberts. (2013). Potential graphite materials for the synthesis of GICs Journal of Chemical Engineering Communications. [Online]. Available:

http://www.tandfonline.com/doi/abs/10.1080/00986445.2013.850580

[11] H. M. A. Asghar, S. N. Hussain, H. Sattar, N. W. Brown, and E. P. L. Roberts, "Electrochemically synthesized GIC-based adsorbents for water treatment using adsorption and electrochemical regeneration," Journal of Industrial \& Engineering Chemistry, vol. 20, no. 4, pp. 2200-2207, 2013

[12] H. M. A. Asghar, S. N. Hussain, H. Sattar, N. W. Brown, and E. P. L Roberts, "Environmentally friendly preparation of exfoliated graphite," Journal of Industrial \& Engineering Chemistry, vol. 20, no. 4, pp. 1936-1941, 2013

[13] H. M. A. Asghar, S. N. Hussain, N. W. Brown, and E. P. L. Roberts, "Synthesis of electrically conducting adsorbents for waste-water treatment using adsorption and electrochemical regeneration," Journal of Industrial \& Engineering Chemistry, vol. 20. pp. 781-786, 2013.
[14] H. M. A. Asghar, S. N. Hussain, E. P. L. Roberts, and N. W. Brown, "Removal of humic acid from water using adsorption coupled-with electrochemical regeneration," The Korean Journal of Chemical Engineering, vol. 30, no. 7, pp. 1415-1422, 2013.

[15] H. M. A. Asghar, S. N. Hussain, E. P. L. Roberts, A. K. Campen, and N W. Brown, "Pretreatment of adsorbent for waste water treatment using adsorption coupled with electrochemical regeneration," Journal of Industrial \& Engineering Chemistry, vol. 19, no. 5, pp. 1689-1696, 2013.

[16] S. N. Hussain, H. M. A. Asghar, A. K. Campen, N. W. Brown, and E. P. L. Roberts, "Breakdown products formed due to oxidation of adsorbed phenol by electrochemical regeneration of a graphite adsorbent," Electrochimica Acta, vol. 110, pp. 150-159, 2013.

[17] S. N. Hussain, E. P. L. Roberts, H. M. A. Asghar, A. K. Campen, and N. W. Brown, "Oxidation of Phenol and the adsorption of breakdown products using a graphite adsorbent with electrochemical regeneration," Electrochimica Acta, vol. 92, pp. 20-30, 2013.

[18] H. M. A. Asghar, E. P. L. Roberts, S. N. Hussain, A. K. Campen, and N. W. Brown, "Wastewater treatment by adsorption with electrochemical regeneration using graphite based adsorbents," Journal of Applied Electrochemistry, vol. 42, no. 9, pp. 797-807, 2012

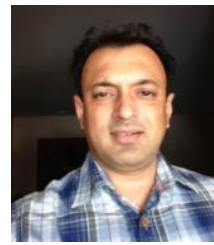

H. M. Anwaar Asghar completed his $\mathrm{PhD}$ in chemical engineering from the University of Manchester, UK in 2011. He has the privilege to conduct his research work on an innovative and energy efficient waste water treatment technology called the Arvia Technology Ltd. Soon after his graduation in chemical engineering, he was appointed as a shift engineer at polyester plant administered by Rupaly Polyester Pvt. Ltd. After getting two years of hands on experience, he switched his career in academics in early 2003 as a lecturer of chemical engineering. He has been serving as a lecturer and then an assistant professor of chemical engineering for the last 12 years. In the mean while he has published 22 research articles in peer reviewed journals of national and international repute with a total impact factor of 32 . He has presented/published 14 articles/extended abstracts in proceedings of the international conferences organized globally. $\mathrm{He}$ is considered to be an eminent expert in waste water treatment technologies. In addition to his expert areas, he is keen to deal with three phase inverse fluidization and reverse osmosis methods for water and gas cleaning processes. 
